\title{
Racial and Geographic Differences in Prevalence, Awareness, Treatment and Control of Dyslipidemia: The Reasons for Geographic and Racial Differences in Stroke (REGARDS) Study
}

\author{
Richard M. Zweifler ${ }^{a}$ Leslie A. McClure ${ }^{b}$ Virginia J. Howard ${ }^{c}$ Mary Cushman $^{d}$ \\ Martha K. Hovater $^{b}$ Monika M. Safford ${ }^{\mathrm{e}}$ George Howard $^{\mathrm{b}}$ David C. Goff, Jr. ${ }^{f}$ \\ aDivision of Neurology, Sentara Medical Group and Department of Neurology, Eastern Virginia Medical School, \\ Norfolk, Va., Departments of ${ }^{\mathrm{b}}$ Biostatistics and ${ }^{\mathrm{C} E p i d e m i o l o g y, ~ S c h o o l ~ o f ~ P u b l i c ~ H e a l t h, ~ U n i v e r s i t y ~ o f ~ A l a b a m a ~ a t ~}$ \\ Birmingham, Birmingham, Ala., 'Department of Oncology, University of Vermont School of Medicine, Burlington, \\ Vt., ${ }^{e}$ Department of Medicine, Division of Preventive Medicine, University of Alabama at Birmingham, Birmingham, \\ Ala., and ${ }^{\mathrm{f}}$ Division of Public Health Sciences, Wake Forest University School of Medicine, Winston-Salem, N.C., USA
}

\section{Key Words}

Cholesterol $\cdot$ Risk factors $\cdot$ Risk factor management $\cdot$ Racial differences $\cdot$ Stroke prevention

\begin{abstract}
Background/Aims: There are racial and geographic disparities in stroke mortality, with higher rates among African Americans (AAs) and those living in the southeastern US ('stroke belt'). Racial and geographic differences in dyslipidemia prevalence, awareness, treatment and control may, in part, account for the observed disparities in stroke mortality. Methods: Reasons for Geographic and Racial Differences in Stroke (REGARDS) is a national observational study of community-dwelling black and white participants aged 45 and older, with oversampling from the stroke belt. As of January $15,2007,26,122$ participants were enrolled and a fasting lipid panel was available of 21,068 . Awareness, treatment and control of dyslipidemia were estimated overall and compared across race-sex-region strata. Results: There were 55\% of the participants with dyslipidemia and no racial differences in prevalence. Adjusting for demographic and established stroke risk factors, AAs had a lower prevalence (OR 0.74; 95\%
\end{abstract}

$\mathrm{Cl}: 0.66,0.77)$ and were less likely to be aware $(0.69 ; 0.61,0.78)$, treated $(0.77 ; 0.67,0.89)$ and controlled $(0.67 ; 0.58,0.77)$ than whites. There was lower control outside of the stroke belt $(0.87 ; 0.76,0.99)$. Conclusion: Racial, but not geographic, differences in dyslipidemia management may play a role in the excess stroke burden in the Southeast.

Copyright ๑ 2011 S. Karger AG, Basel

\section{Introduction}

In the US, there are both racial and geographic disparities in stroke mortality, with African Americans (AAs) and those living in the Southeast (e.g., 'stroke belt') most susceptible $[1,2]$. Although many potential contributors to these disparities have been proposed, the precise explanation(s) remain elusive [3]. While data from the Greater Cincinnati/Northern Kentucky Stroke Study (GCNKSS) suggest that the higher stroke mortality among AAs is attributable to a higher stroke incidence rate rather than a higher case fatality [4], data are much less clear to attribute the geographic disparities to a higher incidence versus a higher case fatality [3]. To the extent

\section{KARGER}

(C) 2011 S. Karger AG, Basel

Fax +41613061234 E-Mail karger@karger.ch www.karger.com www.karger.com/ned
Richard M. Zweifler, MD

Division of Neurology, Sentara Medical Group

600 Gresham Drive, Suite 8630

Norfolk, VA 23507 (USA)

Tel. +1 757388 6133, E-Mail rmzweifl@ sentara.com 
that there are regional and racial differences in incident stroke, it is reasonable to look for disparities in risk factors that could contribute to differences in incidence. Dyslipidemia has emerged as such a risk factor for ischemic stroke [5-8] and studies of statin agents in patients with coronary artery disease (CAD), hypertension, or diabetes have demonstrated a relative risk reduction in stroke incidence of approximately $15-30 \%$ [9-14]. Recently, the Stroke Prevention by Aggressive Reduction in Cholesterol Levels (SPARCL) study reported reductions in stroke and stroke or major coronary events in atorvastatin-treated patients with prior stroke or transient ischemic attack and no symptomatic CAD at baseline [15].

The role of dyslipidemia in explaining racial and geographic disparities in stroke has not been systematically studied. Differences in dyslipidemia prevalence and/or management may account for some of these disparities. As a step in addressing this possibility, we tested the hypothesis that racial (AA vs. white) and/or geographic (stroke belt vs. non-stroke belt) differences exist in dyslipidemia prevalence, awareness, treatment and/or control using a national population sample including a large AA population with oversampling from the stroke belt.

\section{Subjects and Methods}

Data from the Reasons for Geographic and Racial Differences in Stroke (REGARDS) study were used to calculate the rates of prevalence, awareness treatment, and control of dyslipidemia in US AAs versus whites, and in participants living in the stroke belt versus non-stroke belt states. REGARDS is a national longitudinal observational study. Beginning February 2003 through October 2007, 30,228 individuals aged 45 and older were enrolled, with approximately equal representation of whites and AAs, men and women [16]. Twenty-one percent (goal was 20\%) of the sample was selected from the 'buckle' of the stroke belt (coastal plain region of North Carolina, South Carolina, and Georgia, USA), 35\% (goal was $30 \%$ ) from the stroke belt states (remainder of North Carolina, South Carolina, and Georgia, plus Alabama, Mississippi, Tennessee, Arkansas, and Louisiana), and the remaining $45 \%$ (goal was 50\%) from the other 40 contiguous states. Within each region, individuals were recruited using a combination of mail and telephone from commercially available lists of residents. Consent was obtained verbally and later in writing. For those agreeing to participate, self-reported demographic information and cardiovascular risk factors were obtained by computer-assisted telephone interview. Participants were asked 'have you ever been told by a doctor that you have high cholesterol or abnormal level of fats in your blood' and, if they responded yes, 'are you taking any medicine for it?' If the respondent was unsure, some of the common lipid medications were listed to probe. Physical measures were collected at an in-home examination including blood pressure, fasting blood (subsequently assayed for cardiovascular risk factors including a standard lipid panel) and urine samples, electrocardiogram record, and an inventory of current medications. The study methods were reviewed and approved by the Institutional Review Board at the participating centers. Additional methodological details are provided elsewhere [16]. This analysis is based on data through January 15, 2007, at which time 26,122 participants were enrolled and a fasting lipid panel was available of 21,068

Cholesterol measurements were performed following an overnight fast ( $86 \%$ of participants). 'Dyslipidemia' was defined as being on lipid-modifying medication (i.e., treated) or, for those not on therapy, having a low-density-lipoprotein cholesterol (LDL-C), exceeding the clinical risk group-specific threshold in ATP III for consideration of drug therapy. A threshold of $100 \mathrm{mg} / \mathrm{dl}(2.6$ $\mathrm{mmol} / \mathrm{l}$ ) was used for participants in the high- and moderately high-risk categories, $130 \mathrm{mg} / \mathrm{dl}(3.3 \mathrm{mmol} / \mathrm{l})$ for those in the moderate-risk category and $160 \mathrm{mg} / \mathrm{dl}(4.1 \mathrm{mmol} / \mathrm{l})$ for those in the low-risk category [17]. Participants were considered 'undiagnosed' if they were dyslipidemic but neither told by a medical doctor nor on lipid-modifying medication, 'aware' if they were told they were dyslipidemic by a medical doctor, 'treated' if they were aware and on lipid-modifying medication, and 'controlled' if they were on lipid-modifying medication and their LDL-C met the ATP III risk category goal. Use of a statin was recorded for those treated. 'Region' was dichotomized as residence in the stroke belt (including the buckle region) or the remaining 40 contiguous states.

Variables that could potentially confound the relationships between race or region with awareness, treatment and control of dyslipidemia were categorized into 3 broad classes. Demographic variables included age, sex, and current marital status (married or not married). Socioeconomic status variables were years of education (categorized as less than high school, high school graduate, some college, or college graduate), household income (USD $<25,000,25,000-50,000$, and 50,000+), and whether the participant reported having health insurance (answering positively to 'Do you have any kind of healthcare coverage such as health insurance, a Health Maintenance Organization (HMO), or a government plan like Medicare or Medicaid?'). Risk factors considered were diabetes, hypertension, cigarette smoking (categorized as never, past, or current), current alcohol consumption (categorized as none, moderate, or heavy), body mass index (categorized as normal $\leq 24.9$, overweight $25-29.9$ or obese $\geq 30$ ), and frequency of exercise (categorized by the question 'How many times per week do you engage in intense physical activity, enough to work up a sweat?' into never, $<5$ times per week, and $\geq 5$ times per week). Diabetes was defined as a fasting glucose level greater than $126 \mathrm{ml} / \mathrm{dl}(7 \mathrm{mmol} / \mathrm{l})$, nonfasting glucose greater than $200 \mathrm{ml} / \mathrm{dl}$ $(11.1 \mathrm{mmol} / \mathrm{l})$, or self-reported medication use for glucose control.

\section{Statistical Analysis}

The same analytic approach was taken to assess racial and regional differences in prevalence and for each of the 3 management outcomes (awareness, treatment, and control). First, univariate analysis was conducted to show the likelihood of having dyslipidemia or of being aware, treated, or controlled within strata defined by race, region, demographic factors, measures of socioeconomic status, and risk factors. Logistic regression analysis was then used to estimate the odds ratio (OR) for prevalence and each of the 3 outcomes in an incremental series of models that progressed from considering race and region to adding demographic 
factors, then adding socioeconomic factors, and finally adding risk factors. Because of the sampling design of REGARDS, the regional differences are reported after adjustment for race, and the racial differences are reported after adjustment for region.

\section{Results}

Of the participants included in these analyses, $40 \%$ were AA, $60 \%$ were white and $55 \%$ lived in the stroke belt. The overall mean (SD) age was 65 (9.3) ranging from 45 to 94 years. The mean (SD) total and LDL-C were 192 (39) $\mathrm{mg} / \mathrm{dl}[4.9(1.0) \mathrm{mmol} / \mathrm{l}]$ and $115(35) \mathrm{mg} / \mathrm{dl}[2.9(0.9)$ $\mathrm{mmol} / \mathrm{l}]$, respectively. Overall, $1,346(6 \%)$ reported a stroke and 3,873 (18\%) had heart disease.

Overall, 55\% were dyslipidemic, and higher proportions of individuals with the following characteristics had dyslipidemia: male gender, older age, less education, lower income, less health insurance, diabetes, obesity, current or past smoking and abstinence from alcohol and exercise (table 1). Prior to adjustment, there was no statistically significant difference in prevalence of dyslipidemia by region or race. Using the $130 \mathrm{mg} / \mathrm{dl}(3.3 \mathrm{mmol} / \mathrm{l})$ cutoff, dyslipidemia prevalence decreased to $47 \%$ overall with no racial differences ( $48 \%$ white and $47 \%$ black).

Prior to adjustment, there were no geographic differences in dyslipidemia awareness or treatment but control was modestly higher in the stroke belt ( 73 vs. $70 \%$; $p=$ $0.02)$. As regards racial differences, more whites were aware ( 81 vs. $75 \%$; p < 0.001 ), treated ( 83 vs. $79 \%$; $p<$ $0.001)$ and controlled (77 vs. $63 \% ; \mathrm{p}<0.001)$. Of the treated participants, $91 \%$ were taking a statin. Although fewer AAs were treated, slightly more of the treated AAs were taking a statin ( 94 vs. $90 \%$; $<<0.001$ ). Higher proportions of individuals with the following other characteristics were aware, treated and controlled: being married, higher income, health insurance, diabetes, hypertension, lower BMI and not currently smoking. More females were aware (82 vs. $75 \%$; $\mathrm{p}<0.001)$ but were equally treated and controlled compared with males. Higher proportions of individuals with more years of education were aware and controlled, but education was not associated with treatment. More individuals of advancing age were aware and treated but age was not associated with control.

Multivariate modeling indicated lower dyslipidemia prevalence in AAs (OR $=0.74 ; 95 \% \mathrm{CI}: 0.66-0.77)$ and persistence of racial differences in awareness, treatment and control (table 2). AAs were significantly less likely to be aware $(\mathrm{OR}=0.69 ; 95 \% \mathrm{CI}: 0.61-0.78)$, treated $(\mathrm{OR}=$ 0.77 ; $95 \%$ CI: $0.67-0.89)$, or controlled $(\mathrm{OR}=0.67 ; 95 \% \mathrm{CI}$ :
0.58-0.77) after controlling for demographics, socioeconomic status, and stroke risk factors. The unadjusted and risk factor-adjusted mean LDL-C levels were higher in AAs versus whites $[118.0 \mathrm{mg} / \mathrm{dl}(3.0 \mathrm{mmol} / \mathrm{l})$ vs. $113 \mathrm{mg} /$ $\mathrm{dl}(2.9 \mathrm{mmol} / \mathrm{l}), \mathrm{p}<0.001$ and $114 \mathrm{mg} / \mathrm{dl}(2.9 \mathrm{mmol} / \mathrm{l}) \mathrm{vs}$. $108 \mathrm{mg} / \mathrm{dl}(2.8 \mathrm{mmol} / \mathrm{l}), \mathrm{p}<0.001$, respectively]. Following adjustment, there were no differences in awareness or treatment by geography; control was lower outside of the stroke belt $(\mathrm{OR}=0.87 ; 95 \%$ CI: 0.76-0.99).

\section{Discussion}

Using ATP III criteria, we found an overall dyslipidemia prevalence of $55 \%$ in a national, biracial, middleaged to elderly cohort. Not unexpectedly, this exceeds the prevalence found in the Multi-Ethnic Study of Atherosclerosis (MESA) as that study enrolled subjects free of CAD [18] and the National Health and Nutrition Examination Survey (NHANES) 1999-2004, which reported a prevalence of $25 \%$, as that study enrolled subjects as young as 20 years [19]. In addition, application of modified ATP III criteria using the more aggressive $100 \mathrm{mg} / \mathrm{dl}$ $(2.6 \mathrm{mmol} / \mathrm{l})$ cutoff explains some of the higher prevalence compared with older studies. In REGARDS, 79\% of dyslipidemic patients were aware of their diagnosis and $82 \%$ were treated, $91 \%$ with a statin. Overall, $72 \%$ of the treated persons were controlled; this compares favorably with prior studies such as NHANES 1999-2004 which reported a $25 \%$ control rate in those with high cholesterol [19], the Lipid Treatment Assessment Project (L-TAP) which found only a $38 \%$ success rate in achieving NCEP (National Cholesterol Education Program) target LDL-C levels in community practice [20], and the MESA, which found a $41.7 \%$ control overall and a $75.2 \%$ control among treated persons [18]

We found no geographic differences in dyslipidemia awareness or treatment but did find a 13\% lower control outside of the stroke belt. These results indicate that differences in dyslipidemia management do not account for the excess stroke burden seen in the Southeast.

REGARDS found no racial differences in the prevalence of dyslipidemia but AAs were less likely to be aware, treated or controlled than whites. Lower rates of awareness, treatment or control in AAs have been reported in previous studies [18, 20-22]. Unlike MESA [18, 23], racial differences in treatment and control were not significantly attenuated by adjustment for access and socioeconomic variables and risk factors. Furthermore, the OR for AA control is less than for treatment (0.65 vs. 0.80$)$. Addi- 
Table 1. Association of demographic, socioeconomic status and risk factors with dyslipidemia prevalence, awareness, treatment and control

\begin{tabular}{|c|c|c|c|c|c|c|c|c|}
\hline & $\begin{array}{l}\text { Prevalence of } \\
\text { dyslipidemia } \\
\mathrm{n}(\%)\end{array}$ & $\begin{array}{l}\mathrm{p} \\
\text { value }\end{array}$ & $\begin{array}{l}\text { Aware of } \\
\text { dyslipidemia } \\
\text { n (\%) }\end{array}$ & $\begin{array}{l}\mathrm{p} \\
\text { value }\end{array}$ & $\begin{array}{l}\text { On medi- } \\
\text { cation } \\
\mathrm{n}(\%)\end{array}$ & $\begin{array}{l}\mathrm{p} \\
\text { value }\end{array}$ & $\begin{array}{l}\text { Controlled } \\
\text { lipids } \\
\mathrm{n}(\%)\end{array}$ & $\begin{array}{l}\mathrm{p} \\
\text { value }\end{array}$ \\
\hline All & $11,375(55)$ & & $8,893(79)$ & & $7,263(82)$ & & $4,740(72)$ & \\
\hline \multicolumn{9}{|l|}{ Race } \\
\hline White & $6,689(54)$ & 0.0653 & $5,405(81)$ & $<0.0001$ & $4,500(83)$ & $<0.0001$ & $3,164(77)$ & $<0.0001$ \\
\hline $\mathrm{AA}$ & $4,686(55)$ & & $3,488(75)$ & & $2,763(79)$ & & $1,576(63)$ & \\
\hline \multicolumn{9}{|l|}{ Region } \\
\hline Other regions & $5,159(55)$ & 0.5680 & $3,999(78)$ & 0.1137 & $3,255(82)$ & 0.5736 & $2,075(70)$ & 0.0207 \\
\hline Stroke belt & $6,208(54)$ & & $4,886(79)$ & & $4,001(82)$ & & $2,662(73)$ & \\
\hline \multicolumn{9}{|l|}{ Sex } \\
\hline Female & $5,705(49)$ & $<0.0001$ & $4,647(82)$ & $<0.0001$ & $3,771(81)$ & 0.2022 & $2,487(73)$ & 0.0948 \\
\hline Male & $5,671(61)$ & & $4,247(75)$ & & $3,493(82)$ & & $2,255(71)$ & \\
\hline \multicolumn{9}{|l|}{ Age group (years) } \\
\hline $45-54$ & $797(34)$ & $<0.0001$ & $596(75)$ & $<0.0001$ & $463(78)$ & 0.0003 & $294(71)$ & 0.8656 \\
\hline $55-64$ & $4,172(51)$ & & $3,303(80)$ & & $2,654(80)$ & & $1,753(72)$ & \\
\hline $65-74$ & $4,208(62)$ & & $3,386(81)$ & & $2,793(83)$ & & $1,815(72)$ & \\
\hline $75-84$ & $1,963(64)$ & & $1,453(74)$ & & $1,230(85)$ & & $795(72)$ & \\
\hline $85+$ & $234(59)$ & & $154(66)$ & & $122(80)$ & & $82(75)$ & \\
\hline \multicolumn{9}{|l|}{ Currently married } \\
\hline No & $4,605(54)$ & 0.2810 & $3,555(78)$ & 0.0396 & $2,864(81)$ & 0.0316 & $1,753(68)$ & $<0.0001$ \\
\hline Yes & $6,766(55)$ & & $5,335(79)$ & & $4,398(83)$ & & $2,986(74)$ & \\
\hline \multicolumn{9}{|l|}{ Urban/rural status } \\
\hline Rural & $2,118(53)$ & 0.2192 & $1,682(80)$ & 0.2357 & $1,404(84)$ & 0.0953 & $930(73)$ & 0.0514 \\
\hline Mixed & $1,100(54)$ & & $868(79)$ & & $713(82)$ & & $488(75)$ & \\
\hline Urban & $8,161(55)$ & & $6,346(78)$ & & $5,149(81)$ & & $3,325(71)$ & \\
\hline \multicolumn{9}{|l|}{ Years of education } \\
\hline Not HS & $1,670(65)$ & $<0.0001$ & $1,214(73)$ & $<0.0001$ & $988(82)$ & 0.4551 & $562(64)$ & $<0.0001$ \\
\hline Graduate HS & $3,121(57)$ & & $2,457(79)$ & & $1,982(81)$ & & $1,272(70)$ & \\
\hline Some college & $2,943(53)$ & & $2,286(78)$ & & $1,881(82)$ & & $1,209(70)$ & \\
\hline Graduate college & $3,635(50)$ & & $2,935(81)$ & & $2,411(82)$ & & $1,698(77)$ & \\
\hline \multicolumn{9}{|l|}{ Income (USD) } \\
\hline$\leq 25,000$ & $3,420(60)$ & $<0.0001$ & $2,551(75)$ & $<0.0001$ & $2,031(80)$ & 0.0017 & $1,181(64)$ & $<0.0001$ \\
\hline $25,000-50,000$ & $3,583(55)$ & & $2,804(79)$ & & $2,294(82)$ & & $1,521(73)$ & \\
\hline$\geq 50,000$ & $3,024(49)$ & & $2,460(82)$ & & $2,055(84)$ & & $1,483(79)$ & \\
\hline \multicolumn{9}{|l|}{ Health insurance } \\
\hline Yes & $10,743(55)$ & $<0.0001$ & 8,467 (79) & $<0.0001$ & $6,960(82)$ & $<0.0001$ & $4,576(72)$ & $<0.0001$ \\
\hline No & $627(47)$ & & $424(68)$ & & $302(71)$ & & $163(59)$ & \\
\hline \multicolumn{9}{|l|}{ Diabetes } \\
\hline No & $7,755(48)$ & $<0.0001$ & $6,082(79)$ & 0.0140 & $4,881(80)$ & 0.0008 & $3,513(76)$ & $<0.0001$ \\
\hline Yes & $3,331(78)$ & & $2,543(77)$ & & $2,119(83)$ & & $1,202(61)$ & \\
\hline \multicolumn{9}{|l|}{ Hypertension } \\
\hline No & $3,531(41)$ & $<0.0001$ & $2,692(77)$ & 0.0005 & $2,096(78)$ & $<0.0001$ & $1,504(77)$ & $<0.0001$ \\
\hline Yes & $7,756(65)$ & & $6,134(79)$ & & $5,109(83)$ & & $3,207(70)$ & \\
\hline \multicolumn{9}{|l|}{ BMI category } \\
\hline Underweight/normal & $2,297(44)$ & $<0.0001$ & $1,743(76)$ & 0.0126 & $1,384(79)$ & 0.0038 & $960(76)$ & $<0.0001$ \\
\hline Overweight & $4,301(56)$ & & $3,404(79)$ & & $2,772(82)$ & & $1,862(73)$ & \\
\hline Obese & $4,647(60)$ & & $3,646(79)$ & & $3,028(83)$ & & $1,868(69)$ & \\
\hline \multicolumn{9}{|l|}{ Smoker } \\
\hline Never & $4,490(48)$ & $<0.0001$ & $3,578(80)$ & $<0.0001$ & $2,954(83)$ & $<0.0001$ & $2,012(74)$ & $<0.0001$ \\
\hline Past & $5,040(60)$ & & $4,023(80)$ & & $3,348(83)$ & & $2,172(72)$ & \\
\hline Current & $1,817(61)$ & & $1,270(70)$ & & $943(74)$ & & $547(65)$ & \\
\hline \multicolumn{9}{|l|}{ Alcohol consumption } \\
\hline None & $5,756(58)$ & $<0.0001$ & $4,424(77)$ & 0.0012 & $3,621(82)$ & 0.3349 & $2,252(68)$ & $<0.0001$ \\
\hline Moderate & $4,637(51)$ & & $3,707(80)$ & & $3,009(81)$ & & $2,069(76)$ & \\
\hline Heavy & $756(53)$ & & $589(78)$ & & $492(84)$ & & $339(76)$ & \\
\hline \multicolumn{9}{|l|}{ Exercise per week } \\
\hline None & $4,066(58)$ & $<0.0001$ & $3,151(78)$ & 0.4101 & $2,594(82)$ & 0.1134 & $1,628(69)$ & 0.0010 \\
\hline$<5$ & $3,808(53)$ & & 3,001 (79) & & $2,467(82)$ & & $1,656(74)$ & \\
\hline$\geq 5$ & $2,417(53)$ & & $1,883(78)$ & & $1,512(80)$ & & $1,026(74)$ & \\
\hline
\end{tabular}

HS = High school. 
Table 2. Multivariate model of racial and geographic differences in prevalence, awareness, treatment and control of dyslipidemia

\begin{tabular}{lllll}
\hline & & & Unadjusted & $\begin{array}{c}\text { Demographic + SES + risk } \\
\text { factor adjusted }\end{array}$ \\
\hline Prevalence & race & black vs. white & $1.05(1.00-1.11)$ & $0.74(0.66-0.77)$ \\
& region & other regions vs. stroke belt & $1.02(0.96-1.07)$ & $1.01(0.94-1.09)$ \\
Awareness & race & black vs. white & $0.69(0.63-0.75)$ & $0.69(0.61-0.78)$ \\
& region & other regions vs. stroke belt & $0.93(0.85-1.02)$ & $0.92(0.83-1.03)$ \\
Treatment & race & black vs. white & $0.77(0.69-0.86)$ & $0.77(0.67-0.89)$ \\
& region & other regions vs. stroke belt & $0.97(0.87-1.08)$ & $0.95(0.83-1.08)$ \\
& race & black vs. white & $0.52(0.47-0.58)$ & $0.67(0.58-0.77)$ \\
& region & other regions vs. stroke belt & $0.88(0.79-0.98)$ & $0.87(0.76-0.99)$ \\
\hline
\end{tabular}

Demographic $=$ Control for age, sex, marital status, urban/rural; SES = socioeconomic status: further adjustment for income, education, insurance status; risk factor adjusted = further adjustment for diabetes, hypertension, smoking, alcohol use, physical activity level, and BMI.

tional studies are required to further investigate why treated AAs are less likely to achieve control. The REGARDS study supports the hypothesis that some of the excess stroke mortality in AAs may be related to differences in lipid control.

A recent meta-analysis of statin trials has indicated that each $39 \mathrm{mg} / \mathrm{dl}(1.0 \mathrm{mmol} / \mathrm{l})$ reduction in LDL-C is estimated to reduce the risk of all strokes by $21.1 \%$ [23]. Therefore, the risk factor-adjusted difference in LDL-C of $6.2 \mathrm{mg} / \mathrm{dl}(0.16 \mathrm{mmol} / \mathrm{l} ; 5.8 \%)$ in AAs versus whites translates into a predicted stroke excess of 3.4\% in REGARDS AAs. The differences in cholesterol we observed would account for 2,720 additional strokes in US AAs annually (3.4\% of an estimated 80,000 excess strokes in AAs) [4]. These strokes represent potentially avoidable events.

Although optimal stroke prevention strategies must focus on the total risk profile, understanding potential racial and/or geographic disparities in individual risk components is important. Significant improvements in the management of dyslipidemia are needed and should target populations such as AAs. Two national health objectives by 2010 were to reduce to $17 \%$ the prevalence of high blood cholesterol in US adults and to increase to $80 \%$ the proportion of adults who had their blood cholesterol checked during the preceding 5 years [24]. In order to achieve such goals, increased public and professional awareness of cholesterol and increased emphasis on treatment and control by public health agencies and their partners are imperative [25].

Our study is a large, comprehensive epidemiologic evaluation of racial and geographic differences in dyslipidemia but it does have some limitations. Abdominal aor- tic aneurysm is considered a CAD risk equivalent in ATP III and the REGARDS baseline questionnaire did not include these data. We estimate very few participants were miscategorized due to this limitation since studies indicate CAD and other risk factors leading to elevated Framingham Coronary Risk Score are associated with abdominal aortic aneurysm. We also had limited ability to uncover mechanisms leading to the observed differences, underscoring the need for additional study of why AAs are less likely to achieve control.

\section{Conclusion}

In the REGARDS study, AAs with dyslipidemia were less likely to be aware, treated or adequately controlled compared with whites. Inadequate treatment of dyslipidemia may explain some of the excess stroke burden in AAs. We found no evidence to support the contention that geographic differences in dyslipidemia management play a role in the excess stroke burden in the Southeast. Further research investigating the mechanisms for lower lipid control in AAs and targeted interventions to overcome those mechanisms are needed.

\section{Acknowledgements and Funding}

The REGARDS research project is supported by a cooperative agreement U01 NS041588 from the National Institute of Neurological Disorders and Stroke, National Institutes of Health, Department of Health and Human Services. As such, representatives of the funding agency were involved in the review and approval 
of the manuscript but were not directly involved in the design and conduct of the study; collection, management, analysis or interpretation of the data, or preparation of the manuscript.

The authors acknowledge the participating investigators and institutions for their valuable contributions: The University of Alabama at Birmingham, Birmingham, Ala. (Study PI, Data Coordinating Center, Survey Research Unit): George Howard, DrPH, Leslie McClure, PhD, Virginia Howard, PhD, Libby Wagner, MA, Virginia Wadley, PhD, Rodney Go, PhD; University of Vermont (Central Laboratory): Mary Cushman, MD; Wake Forest University (ECG Reading Center): Ron Prineas, MD, PhD; Alabama Neurological Institute (Stroke Validation Center, Medical Monitoring): Camilo Gomez, MD, Susana Bowling, MD; University of Arkansas for Medical Sciences (Survey Research): LeaVonne Pul- ley, PhD; University of Cincinnati (Clinical Neuroepidemiology): Brett Kissela, MD, Dawn Kleindorfer, MD; Examination Management Services Incorporated (In-Person Visits): Andra Graham; Medical University of South Carolina (Migration Analysis Center): Daniel Lackland, PhD; Indiana University (Neuropsychology Center): Frederick Unverzagt, PhD; National Institute of Neurological Disorders and Stroke, National Institutes of Health (funding agency): Claudia Moy, PhD.

\section{Disclosure Statement}

None.

\section{References}

-1 Howard G, Anderson R, Sorlie P, Andrews V, Backlund E, Burke GL: Ethnic differences in stroke mortality between non-Hispanic whites, Hispanic whites, and blacks: the National Longitudinal Mortality Study. Stroke 1994;25:2120-2125.

-2 Lanska DJ: Geographic distribution of stroke mortality in the United States: 1939-1941 to 1979-1981. Neurology 1993;43:1839.

-3 Howard G: Why do we have a Stroke Belt in the Southeastern United States? A review of unlikely and uninvestigated potential causes. Am J Med Sci 1999;317:160-167.

4 Kissela B, Schneider A, Kleindorfer D, Khoury J, Miller R, Alwell K, Woo D, Szaflarski J, Gebel J, Moomaw C, Pancioli A, Jauch E, Shukla R, Broderick J: Stroke in a biracial population: the excess burden of stroke among blacks. Stroke 2004;35:426-431.

$\checkmark 5$ Tanne D, Koren-Morag N, Graff E, Goldbourt U: Blood lipids and first-ever ischemic stroke/transient ischemic attack in the Bezafibrate Infarction Prevention (BIP) Registry: high triglycerides constitute an independent risk factor. Circulation 2001;104:2892-2897.

-6 Sacco RL, Benson RT, Kargman DE, BodenAlbala B, Tuck C, Lin IF, Cheng JF, Paik MC, Shea S, Berglund L: High-density lipoprotein cholesterol and ischemic stroke in the elderly: The Northern Manhattan Stroke Study. JAMA 2001;285:2729-2735.

$\checkmark 7$ Koren-Morag N, Tanne D, Graff E, Goldbourt U, Bezafibrate Infarction Prevention Study Group: Low- and high-density lipoprotein cholesterol and ischemic cerebrovascular disease: The Bezafibrate Infarction Prevention Registry. Arch Intern Med 2002; 162:993-999.

$\checkmark 8$ Kurth T, Everett BM, Buring JE, Kase CS, Ridker PM, Gaziano JM: Lipid levels and the risk of ischemic stroke in women. Neurology 2007;68:556-562.

$\checkmark 9$ Heart Protection Study Collaborative Group: Effects of cholesterol-lowering with simvastatin on stroke and other major vascular events in 20,536 people with cerebrovascular disease or other high-risk conditions. Lancet 2004;363:757-767.

10 Amarenco P, Labreuche J, Lavallee P, Touboul PJ: Statins in stroke prevention and carotid atherosclerosis: systematic review and up-to-date meta-analysis. Stroke 2004; 35:2902-2909.

-11 Byington RP, Davis BR, Plehn JF, White HD Baker J, Cobbe SM, Shepherd J: Reduction of stroke events with pravastatin: the Prospective Pravastatin Pooling (PPP) Project. Circulation 2001;103:387-392.

12 Randomized trial of cholesterol lowering in 4,444 patients with coronary heart disease: the Scandinavian Simvistatin Survival Study (4S). Lancet 1994;344:1383-1389.

-13 Sever PS, Dahlof B, Poulter NR, Wedel H, Beevers G, Caulfield M, Collins R, Kjeldsen SE, Kristinsson A, McInnes GT: Prevention of coronary and stroke events with atorvastatin in hypertensive patients who have average or lower-than-average cholesterol concentrations, in the Anglo-Scandinavian Cardiac Outcomes Trial-Lipid Lowering Arm (ASCOT-LLA): a multicentre randomised controlled trial. Lancet 2003;361:1149-1158.

14 Cholesterol Treatment Trialists' (CTT) Collaboration: Efficacy and safety of more intensive lowering of LDL cholesterol: a metaanalysis of data from 170,000 participants in 26 randomized trials. Lancet 2010;376:1670 1681.

15 Amarenco P, Bogousslavsky J, Callahan A 3rd, et al., Stroke Prevention by Aggressive Reduction in Cholesterol Levels (SPARCL) Investigators: High-dose atorvastatin after stroke or transient ischemic attack. N Engl J Med 2006;355:549-559.

16 Howard VJ, Cushman M, Pulley L, Gomez CR, Go RC, Prineas RJ, Graham A, Moy CS, Howard G: The reasons for geographic and racial differences in stroke study: objectives and design. Neuroepidemiology 2005;25:135-143.

17 Grundy SM, Cleeman JI, Merz CNB, Brewer HB Jr, Clark LT, Hunninghake DB, Pasternak RC, Smith SC Jr, Stone NJ, Coordinating
Committee of the National Cholesterol Education Program: A summary of implications of recent clinical trials for the National Cholesterol Education Program Adult Treatment Panel III guidelines. Arterioscler Thromb Vasc Biol 2004;24:1329-1330.

18 Goff DC Jr, Bertoni AG, Kramer H, Bonds D, Blumenthal RS, Tsai MY, Psaty BM: Dyslipidemia prevalence, treatment, and control in the Multi-Ethnic Study of Atherosclerosis (MESA): gender, ethnicity, and coronary artery calcium. Circulation 2006;113:647-656.

19 Hyre AD, Muntner P, Menke A, Raggi P, He J: Trends in ATP-III-defined high blood cholesterol prevalence, awareness, treatment and control among US adults. Ann Epidemiol 2007; 17:548-555.

20 Pearson TA, Laurora I, Chu H, Kafonek S: The Lipid Treatment Assessment Project (LTAP): a multicenter survey to evaluate the percentages of dyslipidemic patients receiving lipid-lowering therapy and achieving low-density lipoprotein cholesterol goals. Arch Intern Med 2000;160:459-467.

21 Litaker D, Koroukian S: Racial differences in lipid-lowering agent use in Medicaid patients with cardiovascular disease. Med Care 2004;42:1009-1018.

22 Massing M, Foley K, Carter-Edwards L, Sueta C, Alexander C, Simpson R: Disparities in lipid management for African Americans and Caucasians with coronary artery disease: a national cross-sectional study. BMC Cardiovasc Disord 2004;4:15.

$>23$ Amarenco P, Labreuche J: Lipid management in the prevention of stroke: review and updated meta-analysis of statins for stroke prevention. Lancet Neurol 2009;8:453-463.

24 US Department of Health and Human Services: Healthy People 2010 (Conference Ed, 2 vol). Washington, US Department of Health and Human Services, 2000.

25 Fan AZ, Greenlund KJ, Dai S, Croft JB: Disparities in screening for an awareness of high blood cholesterol - United States, 19992002. MMWR 2005;54:117-119. 